\title{
Perineural spread by squamous carcinomas of the head and neck: a morphological study using antiaxonal and antimyelin monoclonal antibodies
}

\author{
RL CARTER, CS FOSTER, * ELIZABETH A DINSDALE, * MR PITTAM \\ From the Department of Pathology and Head and Neck Unit, Institute of Cancer Research and Royal \\ Marsden Hospital, London and Sutton; and *The Ludwig Institute for Cancer Research (London Branch), \\ Royal Marsden Hospital, Sutton
}

SUMMARY Perineural spread has been demonstrated histologically in 65/180 (36\%) major surgical resections for squamous carcinomas of the head and neck; the incidence in a smaller necropsy series was $18 / 20$ (90\%). Perineural infiltration was observed most commonly in the vicinity of carcinomas arising in the buccal cavity $(31 / 63,50 \%)$ and, at all sites, it was most commonly encountered near tumours $\geqslant 2.5 \mathrm{~cm}$ in diameter. Perineural spread near cervical node metastases was, by contrast, uncommon in the surgical series. Tumour within perineural spaces tends to be concentrated at the margin of the nerve and shows only limited extension inwards, but cells may track upwards and downwards within the spaces. Distant spread for $>2 \mathrm{~cm}$ is unusual, and interval sampling of involved nerves in necropsy material indicates that most perineural tumour cells are confined to the distal $1 \mathrm{~cm}$ of the affected nerve. Infiltrated nerves regularly show varying degrees of myelin and axonal degeneration, probably anoxic in origin, and segmental infarction of nerve trunks was observed in three patients. Fine changes in axons and myelin have been regularly demonstrated with two monoclonal antibodies, and the use of these new reagents is described.

Infiltrating carcinomas frequently invade perineural spaces which provide a route of further dissemination, notably to the intracranial cavity. The involved nerves are often a source of severe local and referred pain or dysaesthesia. Several descriptions of perineural spread by tumours arising in the breast, skin, lip, lungs, oesophagus and stomach ${ }^{1}$ date from the turn of the century, and a well-illustrated account was published by Ernst in $1907 .{ }^{2}$ Infiltration of perineural spaces was subsequently recognised in other carcinomas, particularly those arising in the pancreas and prostate. The perineural spaces were originally regarded as lymphatics ${ }^{1}$ but they have now been shown to be separate from any part of the organised lymphatic system. ${ }^{34}$

Within the head and neck, perineural spread is particularly associated with adenoid cystic car-

Requests concerning monoclonal antibodies to: Dr CS Foster, Ludwig Institute for Cancer Research, Royal Marsden Hospital, Sutton, Surrey, SM2 5PX, England.

Accepted for publication 13 October 1982 cinomas of the major and minor salivary glands, but it is also a common feature of squamous carcinomas. $^{\text {s-9 }}$ The purpose of the present paper is twofold: (i) to record the incidence of perineural infiltration in a large series of squamous cancers of the head and neck, drawn from both surgical and necropsy material; (ii) to describe the detailed histopathology of the infiltrated nerves using two monoclonal antibodies directed against axonal and myelin components of human nervous tissue.

\section{Patients and methods}

Patients in the surgical series were admitted to the Royal Marsden and King's College Hospitals between 1976 and 1982. Most of the patients in the necropsy series were admitted to St Christopher's Hospice. Surgical specimens and necropsy tissues were dissected in detail in the laboratory, fixed in $10 \%$ formol saline and processed by standard techniques for histopathology. Bone was decalcified in $10 \%$ formic acid. Extra material was stained with methazole fast blue to demonstrate myelin and with 
the Glees-Marsland silver impregnation technique for axons.

\section{MONOCLONAL ANTIBODIES}

\section{Preparation of immunogen}

Human brains were obtained within four hours post mortem from persons dying suddenly and unexpectedly. Brains from patients dying with known malignant or central nervous system diseases were excluded. Brain tissue was sliced, homogenised and salt-fractionated. ${ }^{10}$ The neurone-specific protein fraction was prepared from this precipitate by chromatography on a DEAE 52 cellulose column (Whatman, preswollen). ${ }^{11}$ Enolase (2-phospho-Dglycerate hydrolase) activity was assayed ${ }^{12}$ and three peaks of activity eluted from the column. The fractions containing peak III were pooled and lyophilised.

\section{Preparation of monoclonal antibodies}

Female BALB/c mice aged eight weeks were immunised by the subcutaneous injection of $100 \mu \mathrm{g}$ (protein content) of lyophilised immunogen in 200 $\mu l$ Freund's complete adjuvant. The injections were repeated intraperitoneally at 7 and 14 days and the mice were then "rested" for one month. Three days before cell fusion, the mice received a fourth intraperitoneal injection of $100 \mu \mathrm{g}$ immunogen in sterile normal saline.

Lymphocytes disaggregated from the spleens of the immunised mice were fused with cells of the mouse myeloma line NS1 using polyethylene glycol. The hybridized cells were selectively cultured in Dulbecco's minimal essential medium containing hypoxanthine, aminopterin and thymidine, and cloned from the outset in $0.25 \%$ (wt/vol) agar. ${ }^{13}$ Ten days after cell fusion, cultures producing antibodies were identified using a modified plate-binding assay. ${ }^{14}$ Duplicate aliquots of tissue culture media were incubated in the wells of microtitre plates previously absorbed with the original immunogen. Bound antibody was then detected after incubation with ${ }^{125}$ I-labelled affinity-purified rabbit antimouse immunoglobulin $\mathrm{G}^{15}$ (Sera Lab). Hybridoma colonies picked from positive wells were grown up individually. After 10 days, these culture supernatants were assayed for antibodies binding to the immobilised immunogen.

Positive supernatants were concentrated tenfold with Amicon B-125 ultrafiltration chambers. A wide range of normal human tissue stained immunohistochemically by the concentrated supernatants was examined. The supernatants from two hybridomas showed specific staining (within the nervous system) for myelin sheaths (LICR-LON-E25) and for nerve axons (LICR-LON-E36). These hybridomas were $\frac{0}{7}$ recloned by limiting-dilution before passage as 으 ascites tumours in mice.

\section{IMMUNOHISTOCHEMICAL STAINING OF}

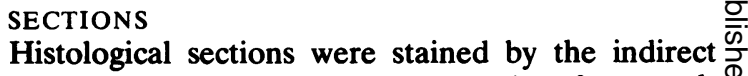
immunophosphatase technique. Ascites from each $\stackrel{\mathbb{}}{\square}$ hybridoma, diluted $1 / 100$ in sodium phosphate buffered saline ( $\mathrm{pH} \mathrm{7.4)} \mathrm{containing} 1 \%(\mathrm{wt} / \mathrm{vol})$ bovine $\vec{\circ}$ serum albumin (PBS-BSA), was employed as the primary immunohistochemical reagent. After rins- $\vec{\omega}$ ing in PBS containing $0.01 \%$ (vol/vol) Tween-80,, bound monoclonal antibodies were identified with a? sheep antimouse immunoglobulin $G$ conjugated to $\omega$ alkaline phosphatase ${ }^{16}$ and visualised using a freshly $\omega$ prepared mixture of Fast Red $(0.5 \mu \mathrm{g} / \mu \mathrm{l})$ and $\mathcal{O}^{-}$ sodium naphthol As-Bl $(0.5 \mu \mathrm{g} / \mu \mathrm{l})$ in $30 \mathrm{ml}$ veronal 6 acetate buffer ( $\mathrm{pH} 9 \cdot 2$ ).

\section{Results}

OVERALL INCIDENCE OF PERINEURAL SPREAD The results in the surgical series of 250 patients are $\varnothing_{\infty}$ summarised in Table 1 . Perineural spread is consi-. $\omega$ dered in two groups: in relation to primary tumours and to metastases in cervical lymph nodes. The overall incidence of perineural spread in the vicinity of the primary tumours is $65 / 180(36 \%)$. It was reported most frequently for carcinomas arising in $\stackrel{\Omega}{\Omega}$ the buccal cavity-31/63 (50\%). At all sites, $\stackrel{2}{\vec{F}}$ perineural infiltration was most commonly seen in association with primary tumours $\geqslant 2.5 \mathrm{~cm}$ in diameter-Table 2. Perineural spread in the vicinityo of cervical node metastases is, by contrast, uncommon and was encountered in only 5 out of 157 radi-?

Table 1 Perineural spread in surgical series (250 patients; $\delta$ 210 men and 40 women; age range 26-86 yr (mean 60 yr))

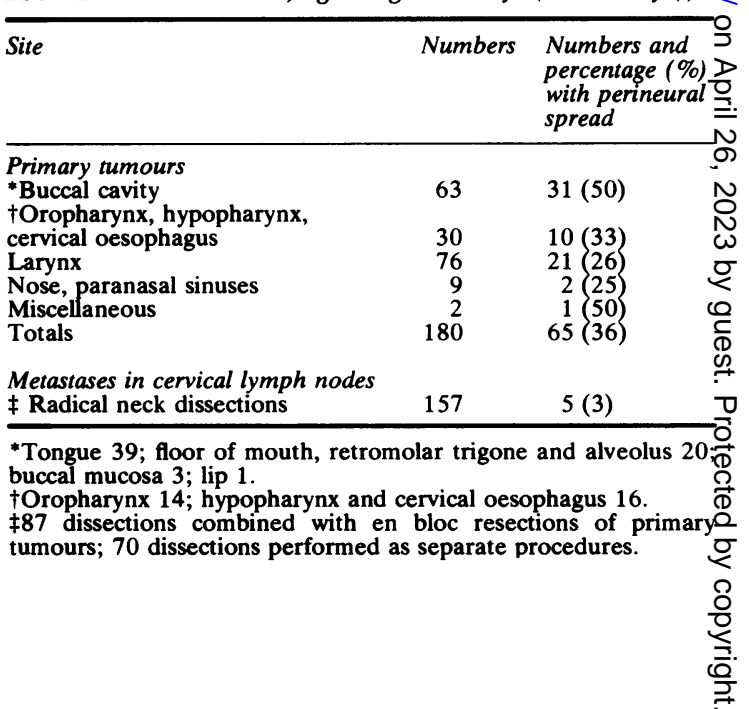


Table 2 Perineural (PN) spread in relation to size of primary tumour in surgical series

\begin{tabular}{|c|c|c|c|}
\hline \multirow[t]{2}{*}{ Site } & \multirow[t]{2}{*}{ Numbers } & \multicolumn{2}{|c|}{ Largest diameter of tumour in resected specimen } \\
\hline & & $<2.5 \mathrm{~cm}$ & $\geqslant 2.5 \mathrm{~cm}$ \\
\hline Buccal cavity & $\left\{\begin{array}{l}\text { PN spread }+31 \\
\text { PN spread }-32\end{array}\right\}$ & $\left\{\begin{array}{r}6 \\
22\end{array}\right.$ & $\begin{array}{l}25 \\
10\end{array}$ \\
\hline $\begin{array}{l}\text { Oropharynx, hypopharynx, } \\
\text { cervical oesophagus }\end{array}$ & $\left\{\begin{array}{l}\text { PN spread }+10 \\
\text { PN spread }-20\end{array}\right\}$ & $\left\{\begin{array}{r}2 \\
14\end{array}\right.$ & $\begin{array}{l}8 \\
6\end{array}$ \\
\hline Larynx & $\left\{\begin{array}{l}\text { PN spread }+21 \\
\text { PN spread }-55\end{array}\right\}$ & $\left\{\begin{array}{r}3 \\
43\end{array}\right.$ & $\begin{array}{l}18 \\
12\end{array}$ \\
\hline Nose, paranasal sinuses & $\left\{\begin{array}{ll}\text { PN spread }+ & 2 \\
\text { PN spread }- & 7\end{array}\right\}$ & $\left\{\begin{array}{l}0 \\
5\end{array}\right.$ & $\begin{array}{l}2 \\
2\end{array}$ \\
\hline Miscellaneous & $\left\{\begin{array}{ll}\text { PN spread }+ & 1 \\
\text { PN spread }- & 1\end{array}\right\}$ & $\{\overline{1}$ & 1 \\
\hline Total & 180 & & \\
\hline All sites & $\left\{\begin{array}{l}\text { PN spread + } 65 \\
\text { PN spread }-115\end{array}\right.$ & $\begin{array}{l}11 \\
85\end{array}$ & $\begin{array}{l}54 \\
30\end{array}$ \\
\hline
\end{tabular}

Table 3 Perineural spread in necropsy series (20 patients; 14 men and 6 women; age range 50-95 yr (mean $67 \mathrm{yr}$ ))

\begin{tabular}{lcc}
\hline $\begin{array}{l}\text { Site of } \\
\text { primary tumour }\end{array}$ & Numbers & $\begin{array}{l}\text { Numbers with } \\
\text { perineural spread }\end{array}$ \\
\hline Buccal cavity & 7 & 7 \\
Oropharynx, hypopharynx & 12 & 10 \\
Nasal cavity & 1 & 1 \\
Total & 20 & $18(90 \%)$ \\
Patients with perineural spread & & \\
In vicinity of primary tumour & & 11 \\
In vicinity of nodal metastases & 3 \\
In both sites & 4 \\
\hline
\end{tabular}

cal neck dissections (3\%). Two of these five patients also showed perineural infiltration near their primary tumours which were removed en bloc with the neck dissection.
The results in the necropsy series of 20 cases are shown in Table 3. The incidence of perineural spread is high-18/20 (90\%). Its general distribution has changed in that proportionately more patients show evidence of perineural infiltration near nodal metastases in the neck-7/20 (35\%).

\section{MORPHOLOGICAL CHANGES OF PERINEURAL SPREAD}

The histological features of perineural infiltration were similar in the surgical and necropsy series and may be summarised as follows. Tumour cells enter perineural spaces and tend to remain at the margins of the nerve trunks, showing little tendency to invade inwards into the nerve bundles (Fig. 1). Perineural tumour can, however, track upwards and downwards within the spaces. Upward spread of 6

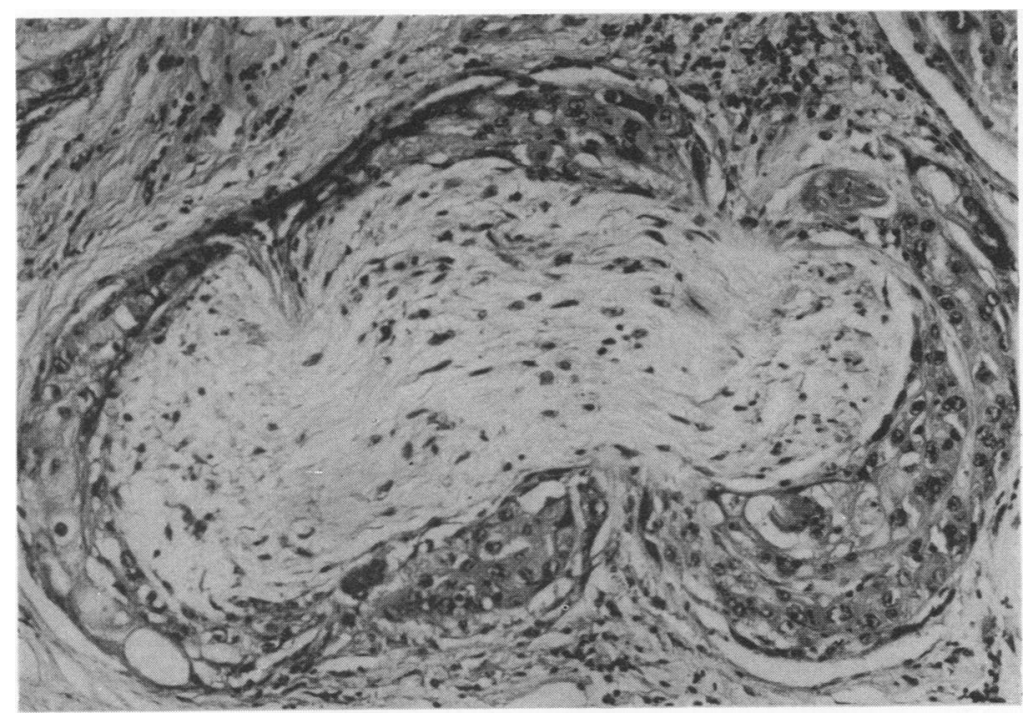

Fig. 1 Squamous carcinoma of the tongue infiltrating perineural spaces of a local nerve deep in the lingual musculature. Some of the Schwann cell nuclei appear degenerate. The patient complained of severe pain in the territory of the mandibular nerve. Haematoxylin and eosin $\times 500$. 


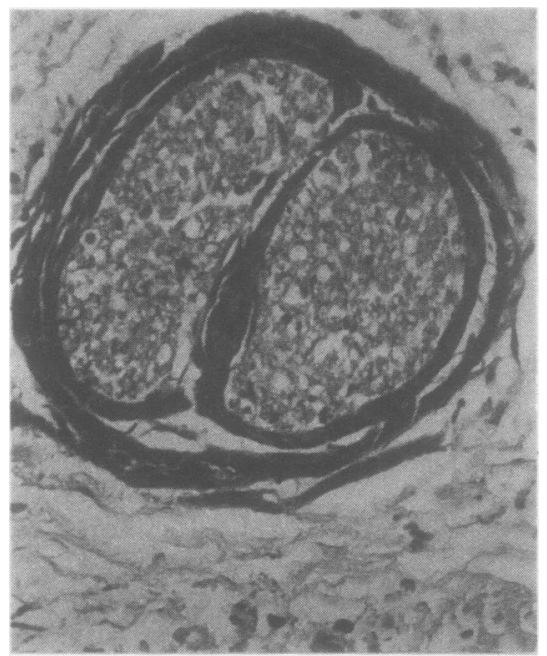

Fig. 2 Squamous carcinoma of the floor of the mouth infiltrating perineural spaces of branches of the inferior dental nerve within the inferior dental canal. Haematoxylin and eosin $\times 225$.

$\mathrm{cm}$ was observed in one surgical case of squamous carcinoma of the external auditory meatus which infiltrated the nerves of the sphenopalatine ganglion in the pterygopalatine fossa. Downward spread of
Carter, Foster, Dinsdale, Pittam

$1-3 \mathrm{~cm}$ was seen in four patients with intraoral car- $\frac{\overbrace{}^{*}}{\overrightarrow{7}}$ cinomas invading along the inferior dental nerve 은 within the mandible (Fig. 2). The extent of $\vec{F}$ perineural spread was examined in more detail in the necropsy patients with sections taken at intervals along fully dissected nerves: in most cases perineural $\frac{\overline{\bar{c}}}{\bar{\rho}}$ tumour was confined to the distal $1 \mathrm{~cm}$ of the nerve $\frac{\vec{\sigma}}{\sigma}$ trunk and more extensive linear invasion was $\propto$ uncommon. Light perineural inflammatory क infiltrates, composed of lymphocytes and mononuc- $\overrightarrow{0}$ lear cells, were an inconsistent feature. Perineural fibrosis, sometimes dense, was seen in heavily $\vec{\omega}$ irradiated tissues.

The nerve trunks themselves may be histologically? intact, but minor degenerative changes were not $\omega$ uncommonly seen in conventionally stained sections $\omega$ (Fig. 1). Foci of Schwann cells developed degener- N ate and pyknotic nuclei, and some of the nerve fibres

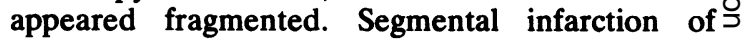
infiltrated nerve trunks was observed in three cases. One surgical patient had an infarcted inferior dental

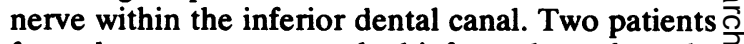
from the necropsy group had infarcted vagal trunks in the neck in association with massive nodal metas- $\infty$ tases and dense postirradiation fibrosis (Fig. 3); direct invasion of the sympathetic chain was also demonstrated. Gross degeneration of axonal and

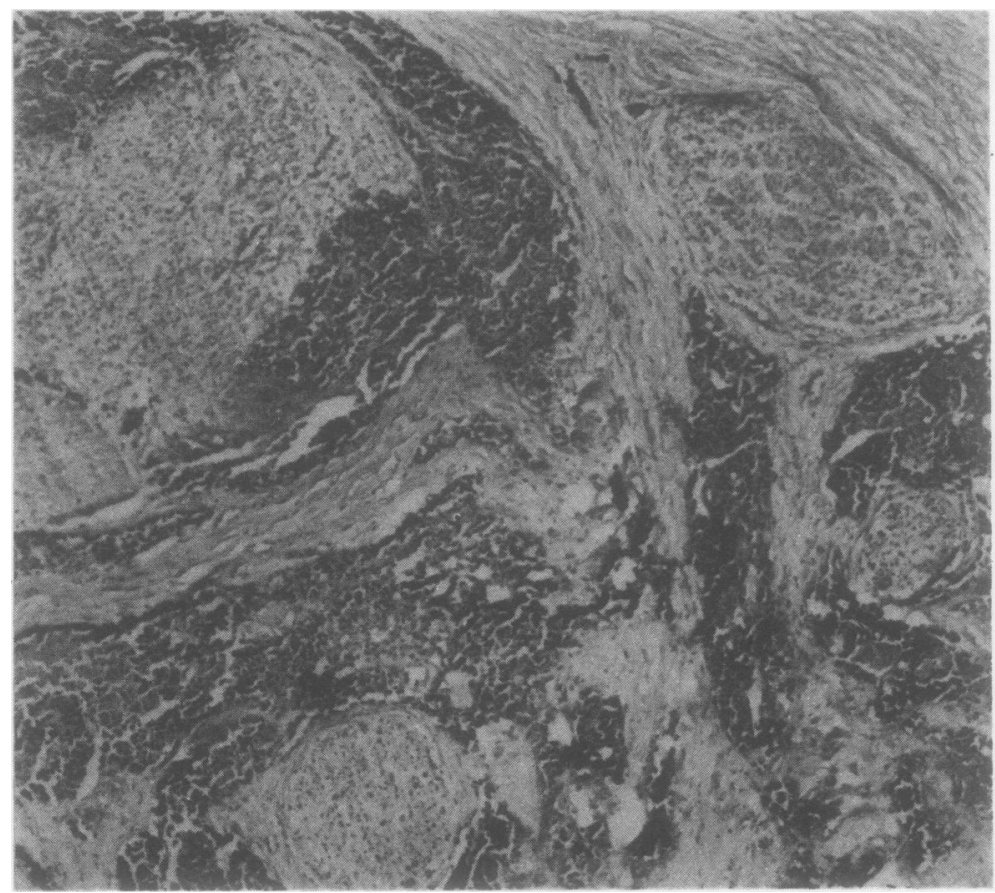

Fig. 3 Infarction of the main vagal trunk in the neck, associated with perineural infiltration from $a$ squamous carcinoma of the oropharynx metastatic to cervical lymph nodes. There is also marked fibrosis. The patient developed complete dysphagia but no local obstruction was found at necropsy (see ref 9). Haematoxylin and eosin $\times 60$. 
Fig. 4 Squamous carcinoma of the floor of the mouth with perineural spread along branches of the inferior dental nerve. Preparation stained with antimyelin monoclonal antibody (LICR-LON-E25). The uninvolved branch on the right side (large curved arrow) shows dark uniform staining of myelin. Two of the involved nerves (straight arrows) also have intact myelin, but the others (small curved arrows) show a variable, patchy loss of stainable myelin. $\times 220$.

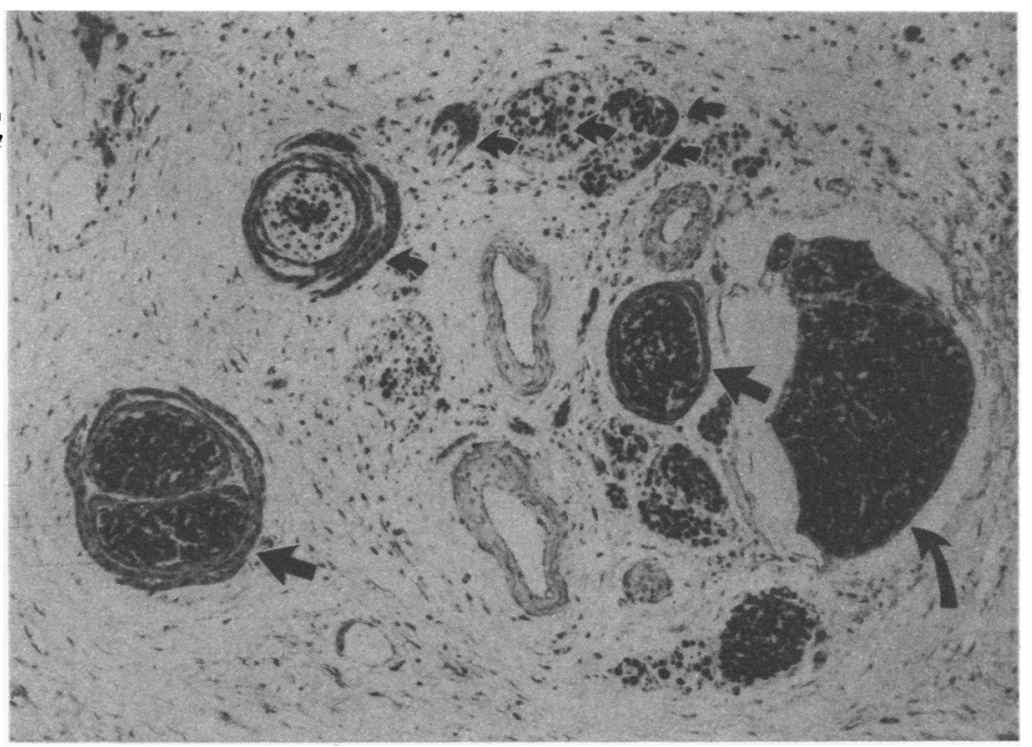

Fig. 5 Squamous carcinoma of the nasal septum infiltrating the facial branches of the maxillary nerve. Preparation stained with anti-axonal monoclonal antibody (LICR-LON-E36). Intact nerve fibres are largely concentrated at one pole of the nerve, opposite the infiltrate. The patient had local anaesthesia, subsequently developed palsies of the facial and abducent nerves, and died of intracranial extension of his tumour. $\times 120$.

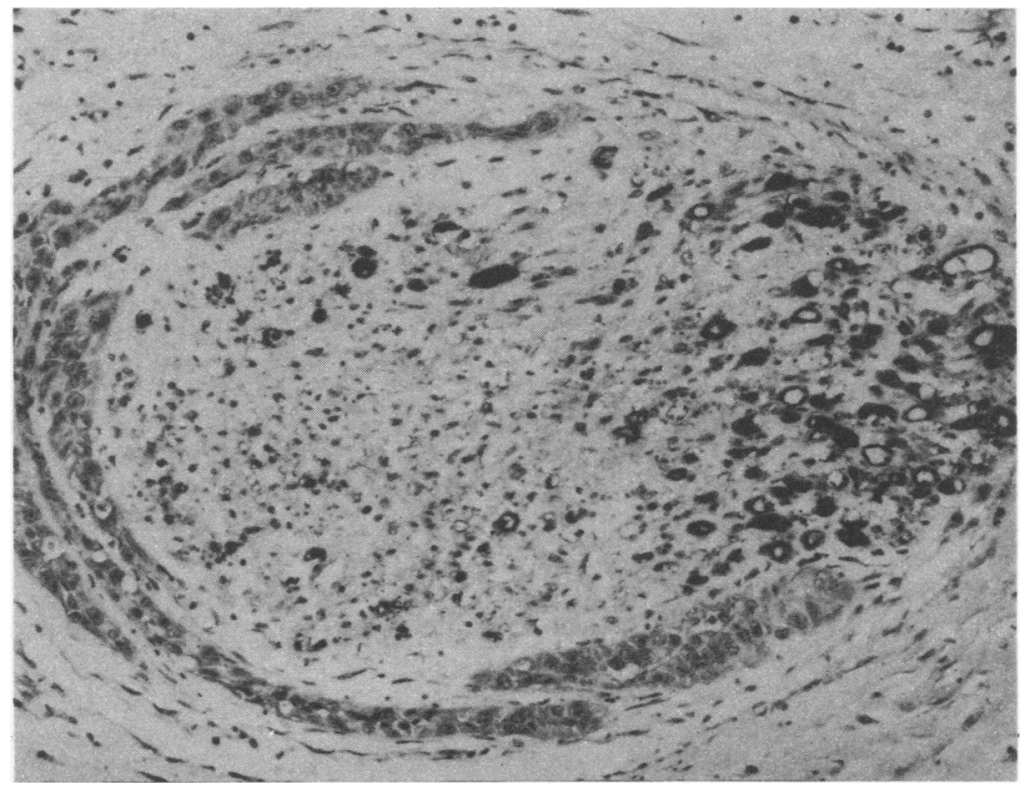


myelin components was confirmed by impregnation techniques.

The occurrence of finer degenerative changes in involved nerves was subsequently examined in more detail with a new immunohistochemical method.

\section{IMMUNOHISTOCHEMICAL CHANGES}

Observations were made with two monoclonal antibodies which identified epitopes within axonal and myelin components of human nervous tissue. In preliminary experiments, both antibodies were shown to be active with surgical and necropsy material fixed in $10 \%$ formol saline, with tissues decalcified in $10 \%$ formic acid, and with tissues stored as paraffin blocks for up to five years. The histological preparations were of consistent quality, they retained fine cytological detail, and they were permanent.

Blocks from 15 cases with perineural infiltrates were examined. Uninvolved nerve trunks showed strong specific staining with both monoclonal antibodies (Fig. 4). Faint weak-positive staining of necrotic debris, keratin and striated muscle was observed in some slides stained with antimyelin antibody, but staining in nerve trunks was not compromised. Most involved nerves showed decreased staining with both antibodies (Figs. 4, 5). This decrease was most marked with the antimyelin antibody so that several nerve trunks lacking stainable myelin still contained some axonal elements. Marked decrease in staining correlated with the abnormalities previously described in infiltrated nerves in standard histological preparations. Only axonal remnants, and no myelin, were demonstrated in infarcted nerve trunks. Small decreases in stainable myelin and axon components were regularly found in nerves which, apart from perineural infiltrates, had appeared intact in conventional sections. Decreased staining in involved nerve trunks was not related to the thickness of the neoplastic infiltrates nor to the presence of perineural inflammatory cells.

\section{Discussion}

The findings reported here confirm the high incidence of perineural spread by squamous carcinomas of the head and neck and demonstrate that many infiltrated nerve trunks sustain damage to axonal and myelin components. The number of patients examined is large and the various sites of the primary tumours are adequately represented, but certain preliminary points should be noted. Carcinomas of the nasopharynx are not included as these tumours are not treated by radical excision. Most of the surgical patients had advanced tumours which, in many instances, had failed to respond to previous $\frac{0}{\vec{*}}$

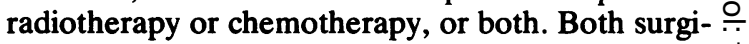
cal and necropsy material was examined in consid- $\overrightarrow{\vec{F}}$ erable detail with at least four blocks, and some- $\frac{\rho}{9}$ times many more, taken from the tumour and its $\frac{\mathrm{C}}{\mathrm{C}}$ immediate environs. The recognition of nerve inva- $\frac{\bar{\omega}}{\bar{\omega}}$ sion in tissue sections was straightforward though $\vec{\nabla}$ possible confusion of perineural spread in the oral $\propto$ cavity with local neuroepithelial embryological is remnants ${ }^{17-20}$ was borne in mind.

Three main findings emerge from the surgical series. Perineural spead of squamous cancer in this $\vec{\omega}$ region is more commonly seen near primary tumours than near nodal metastases in the neck. The? anatomical site of the primary tumour is an impor- $\omega$ tant determinant, largely reflecting differences in the $\omega$ number and distribution of nerve trunks and their $\mathcal{O}$ likely contiguity to invading neoplasm. The size of the primary tumour is also relevant, perineural $\frac{}{5}$ spread being more common in lesions $\geqslant 2.5 \mathrm{~cm}$ in $\vec{z}$ diameter. The difference between perineural

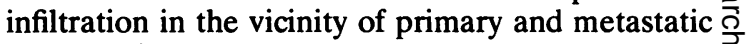
tumours is less apparent in the smaller necropsy $\overrightarrow{\vec{\theta}}$ series where many of the terminal patients had mas- $\infty$ sive nodal and extranodal disease in the neck. The ${ }^{\omega}$ overall incidence of perineural spread in the necropsy group was very high. In both surgical and necropsy series, large squamous carcinomas arising in the buccal cavity are identified as the most likely $\frac{\partial}{\varnothing}$ tumours to spread into the nerve trunks.

The basic histopathological changes of perineural $\overrightarrow{\vec{F}}$ infiltration are familiar. The tumour cells are charac- $\frac{3}{3}$ teristically concentrated within the perineural spaces and do not advance inwards for any distance into the substance of the affected nerve trunks. In a study of the spread of squamous cancers of the head and? neck, Willis s claimed that "medullated nerves enjoy $\overline{3}$ a decided immunity from invasion by epidermoid carcinoma" and commented that he had "yet to see $\frac{O}{3}$ an example of ... invasion and disruption of a microscopic nerve bundle." These views may now be re-examined. Degenerative changes in involved $D$ nerves are sometimes apparent in routinely stained material. Infiltrated nerves occasionally develop No segmental infarction. Staining with sensitive monoclonal antibodies demonstrates that varying degrees 0 of axonal and myelin damage are common in $\omega$ involved nerves, including trunks which appear ${ }^{\circ}$ normal in conventional preparations. It was sug- $\bullet$ gested previously ${ }^{8}$ that the segmental blood supply of nerve trunks is compressed by columns of tumour ${ }^{+}$ cells growing axially along the perineural spaces, $\frac{0}{0}$ and the changes now observed in involved nervesranging from trivial axonal and myelin degeneration $\stackrel{?}{\stackrel{P}{P}}$ to complete infarction-are compatible with differ- $\stackrel{\mathbb{}}{\Omega}$ ent degrees of hypoxic damage. New information 
has also become available on the extent of axial growth of tumour up and down the perineural spaces. Examples of distant spread of several centimetres were encountered here and have been recorded previously; ${ }^{67}$ but interval sampling of nerves in our necropsy series indicates that most perineural tumour is confined to the distal $1 \mathrm{~cm}$ of the affected nerve.

In order to obtain probes which are useful in an analysis of pathological changes, many investigators have sought monoclonal antibodies directed towards the so-called "tissue-specific" antigens. ${ }^{2122} \mathrm{How}$ ever, as we have previously demonstrated ${ }^{23}$ such a requirement is not essential. To be a useful analytical reagent, it is only necessary that a given monoclonal antibody exhibits "within-tissue" specificity and that it binds to a particular tissue in a precise and reproducible manner. Thus, within the nervous system, LICR-LON-E25 only binds to myelin sheaths whereas LICR-LON-E36 binds to nerve axons. With respect to the use of monoclonal antibodies as immunohistochemical reagents, an additional caveat applies to the manner in which the histological tissues are processed, and in particular, the mode of their fixation. Since a particular epitope may be preserved by one fixative but destroyed by another, it is important to specify the method of tissue fixation before comparing the binding of monoclonal antibodies to different tissues. The two monoclonal antibodies (LICR-LON-E25 and LICR-LON-E36) have proved extremely useful in this study. They demonstrate fine structural changes in a specific and reproducible manner, more reliably than the conventional metallic impregnation techniques, and they can be used in formalin-fixed surgical and necropsy tissues which have been decalcified or stored for several years. Their value in detecting degenerative changes in disorders of the central and peripheral nervous system is likely to be considerable.

The authors are indebted to Mr HJ Shaw, Mr Peter Clifford, and Dr Vera Dalley for access to their patients. Financial support is acknowledged from the Medical Research Council (RLC) and the Vandervell Foundation (MRP).

\section{References}

' Willis RA. The spread of tumours in the human body. 3rd ed. London: Butterworths, 1973.

${ }^{2}$ Ernst P. Über das Wachstum und die Verbeitung bösartige Geschwülste insbesondere des Krebses in den Lymphbahnen der Nerven. Beitrage zur Pathologische Anatomie 1907:suppl 7;29-51.

${ }^{3}$ Larson DL, Rodin AE, Roberts DK, O'Steen WK, Rappaport AS, Lewis SR. Perineural lymphatics: myth or fact. Am J Surg 1966;112:488-92.
4 Rodin AE, Larson DL, Roberts DK. Nature of the perineural space invaded by prostate carcinoma. Cancer 1967;20:17729

5 Willis RA. Epidermoid carcinoma of the head and neck, with special reference to metastasis. J Pathol Bacteriol 1930;33:501-19.

- Ballantyne AJ, McCarten AB, Ibanez ML. The extension of cancer of the head and neck through peripheral nerves. Am J Surg 1963;106:651-67.

${ }^{7}$ Dodd GD, Dolan PA, Ballantyne AJ, Ibanez ML, Chau P. The dissemination of tumors of the head and neck via the cranial nerves. Radiol Clin North Am 1970;8:445-61.

${ }^{8}$ Carter RL, Tanner NSB, Clifford P, Shaw HJ. Perineural spread in squamous carcinomas of the head and neck: a clinicopathological study. Clin Otolaryngol 1979;4:271-81.

9 Carter RL, Pittam MR, Tanner NSB. Pain and dysphagia in patients with squamous carcinomas of the head and neck: the role of perineural spread. $J$ Roy Soc Med 1982;75:598-606.

${ }^{10}$ Marangos PJ, Zomzely-Neurath C, York C. Determination and characterization of neuron specific protein (NSP) associated enolase activity. Biochem Biophys Res Comm 1976;68:1309-16.

"Marangos PJ, Zomzely-Neurath C, Goodwin FK. Structural and immunological properties of neuron specific protein (NSP) from rat, cat and human brain: Comparison to bovine 14-3-2. J Neurochem 1977;28:1097-107.

${ }^{12}$ Rider CC, Taylor CB. Enolase isoenzymes in rat tissues. Electrophoretic, chromatographic, immunological and kinetic properties. Biochem Biophys Acta 1974;365:285-300.

${ }^{13}$ Foster CS. Lymphocyte hybridomas. Cancer Treatment Rev 1982;9:59-84.

${ }^{14}$ Foster CS, Edwards PAW, Dinsdale EA, Neville AM. Monoclonal antibodies to the human mammary gland. I. Distribution of determinants in non-neoplastic mammary and extra mammary tissue. Virchows Arch 1982;394:279-93.

is Jensenius JC, Williams AF. The binding of anti-immunoglobulin antibodies to rat thymocytes and thoracic duct lymphocytes. Eur J Immunol 1974;4:91-7.

${ }^{16}$ Avrameas S, Ternynck T. Peroxidase labelled antibody and Fab conjugates with enhanced intracellular penetration. Immunochemistry 1971;8:1175-9.

${ }^{17}$ Lutman GB. Epithelial nests in intraoral sensory nerve endings simulating perineural invasion in patients with oral carcinoma. Am J Clin Pathol 1974;61:275-84.

${ }^{18}$ Endes P, Adler P. Non-malignant perineural spread of epithelial tissue in the orofacial region. Virchows Arch Pathol Anat 1977;374:81-6.

19 Tschen JA, Fechner RE. The juxtaoral organ of Chievitz. Am J Surg Pathol 1979;3:147-50.

${ }^{20}$ Wysocki GP, Wright BA. Intraneural and perineural epithelial structures. Head and Neck Surg 1981;4:69-71.

${ }^{21}$ Cuttitta F, Rosen S, Gazdar AF, Minna JD. Monoclonal antibodies that demonstrate specificity for several types of human lung cancer. Proc Natl Acad Sci USA 1981;78:4591-5.

${ }^{22}$ Seeger RC, Rosenblatt HM, Imai K, Ferrone S. Common antigenic determinants on human melanoma, glioma, neuroblastoma and sarcoma cells defined with monoclonal antibodies. Cancer Res 1981;41:2714-7.

${ }^{23}$ Foster CS, Dinsdale EA, Edwards PAW, Neville AM. Monoclonal antibodies to the human mammary gland: (II) Distribution of determinants in breast carcinomas. Virchows Arch 1982;394:295-305.

Requests for reprints to: Dr RL Carter, Haddow Laboratories, Royal Marsden Hospital, Sutton, Surrey SM2 5PX, England. 